\title{
Antioxidant and antigrowth action of peracetylated oleuropein in thyroid cancer cells
}

\author{
Stefania Bulotta, Rosanna Corradino, Marilena Celano, Jessica Maiuolo, \\ Maria D’Agostino, Manuela Oliverio, Antonio Procopio, Sebastiano Filetti ${ }^{1}$ \\ and Diego Russo \\ Department of Health Sciences, University 'Magna Græcia' of Catanzaro, Viale Europa, Germaneto, \\ Campus 'S. Venuta', 88100 Catanzaro, Italy \\ ${ }^{1}$ Department of Internal Medicine and Medical Specialties, University of Roma 'Sapienza', 00161 Roma, Italy
}

Correspondence should be addressed to D Russo

Email

d.russo@unicz.it

\begin{abstract}
The olive tree phenolic component oleuropein (OLE) and its derivatives have shown many biological properties, thus representing promising novel therapeutics for the treatment of several diseases, including neoplasia. In this study, we evaluated the activities of OLE and its peracetylated derivative (peracetylated oleuropein, Ac-OLE) against two thyroid tumor cell lines that host genotypic alterations detected in human papillary thyroid cancer. TPC- 1 and BCPAP cells were treated with OLE and AC-OLE, and the effects on viability were evaluated by 3-(4,5-dimethylthiazol-2-yl)-2,5-diphenyltetrazolium bromide, cell counting, and trypan blue exclusion assays. Antioxidant effects were analyzed by measuring the reactive oxygen species (ROS) in basal conditions and after treatment with hydrogen peroxide $\left(\mathrm{H}_{2} \mathrm{O}_{2}\right)$. Activity of MAP kinase and PI3K-Akt signaling pathways was evaluated by examining the levels of phosphorylated ERK and Akt by western blot. We found that OLE significantly inhibited the proliferation of both cell lines. This effect was paralleled by a reduction of basal phospho-Akt and phospho-ERK levels and $\mathrm{H}_{2} \mathrm{O}_{2}$-induced ROS levels. A stronger effect was elicited by AC-OLE either in inhibiting cell growth or as an antioxidant, in particular on BCPAP cells. Our results demonstrate that OLE and especially Ac-OLE inhibit in vitro thyroid cancer cell proliferation acting on growth-promoting signal pathways, as well as exerting antioxidant effects. Further studies will reveal the potential application as novel targeted therapeutics in thyroid cancer.
\end{abstract}

Key Words

> oleuropein

thyroid cancer

- MAP kinase

- Akt

- ROS
Journal of Molecular Endocrinology (2013) 51, 181-189

\section{Introduction}

The last decades have registered an increased incidence of differentiated thyroid cancer (DTC), including those unable to concentrate iodide and, for this reason, unresponsive to the current radioiodine-based treatment (Schlumberger et al. 2007, Hall et al. 2009). For these tumors, the search for novel molecular targets and therapeutics still represents a big challenge. Promising results have been obtained by targeting known oncogenedriven alterations of signal transduction pathways mainly involved in thyroid tumor development and progression (Knauf \& Fagin 2009). Thus, novel 'targeted' drugs are currently undergoing clinical testing (Schlumberger \& Sherman 2012). Additional potential therapeutic targets are represented by other molecular alterations detected in 
thyroid cancer cells (Fagin \& Mitsiades 2008). Recently, attention has been focused on the role of oxidative stress and reactive oxygen species (ROS) production in neoplastic transformation and progression (Duracková 2010). Strong evidence suggests a close relationship even between oxidative stress and thyroid cancer (Wang et al. 2011, Xing 2012), encouraging testing of antioxidant molecules as potential novel targeted therapeutics.

Many reports have stated the ability of oleuropein (OLE) and its derivatives, seco-phenolic compounds present in considerable amounts in olive leaves, drupes, and virgin olive oils, to scavenge ROS (Visioli et al. 2002, El \& Karakaya 2009, Cicerale et al. 2010) and inhibit the proliferation of several tumor cell lines (Hamdi \& Castellon 2005, El \& Karakaya 2009, Goulas et al. 2009, Cicerale et al. 2010, Bulotta et al. 2011). Using an innovative extractive method starting from renewable sources of primary matter and adopting sustainable synthetic strategies, we obtained in our laboratory OLE and some acetylated derivatives in good yields and very mild conditions (Procopio et al. 2008, 2009). The latter compounds showed an improved capacity to permeate the molecular membrane, as well as their 'drug likeness' (Procopio et al. 2009). Moreover, when tested against two breast cancer cell lines, the peracetylated compounds revealed a stronger antioxidant and growth-inhibitory activity than OLE (Bulotta et al. 2011).

In this work, we investigated the antiproliferative and antioxidant effects of OLE and its peracetylated derivative (peracetylated oleuropein, Ac-OLE) on two thyroid cancer cell lines, TPC- 1 and BCPAP. These cells are validated models of human papillary thyroid cancer (PTC), in that they host the RET/PTC1 rearrangement and BRAF V600E mutation respectively (Ribeiro et al. 2008, Schweppe et al . 2008), the most common genetic alterations detected in human PTC (Fagin \& Mitsiades 2008). Their tumorigenic action is related to activation of intracellular signaling pathways controlling cell growth and survival (Fagin \& Mitsiades 2008, Schlumberger \& Sherman 2009). For this reason, the effects of OLE and Ac-OLE on the activation of ras-raf-MAPK- and PI3K-Akt-dependent pathways were also investigated.

\section{Subjects and methods}

\section{Chemicals}

OLE and Ac-OLE (Fig. 1) were obtained using a novel sustainable synthetic strategy, as described by Procopio et al. (2009). The following reagents were purchased as

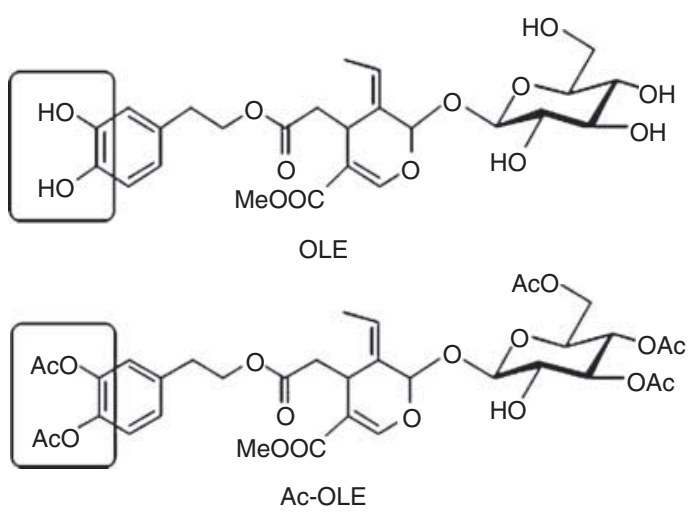

Figure 1

Chemical structures of OLE and AC-OLE. The free catechol moiety (evidenced in squares), responsible for the antioxidant activity of OLE, is protected in AC-OLE with the acetyl group.

indicated: 3-(4,5-dimethylthiazol-2-yl)-2,5-diphenyltetrazolium bromide (MTT), trypan blue solution $(0.4 \%)$, propidium iodide, Triton X-100, RNase A, $2^{\prime}, 7^{\prime}$-dichlorodihydrofluorescein diacetate $\left(\mathrm{H}_{2} \mathrm{DCF}-\mathrm{DA}\right)$, anti- $\beta$-actin $\mathrm{MAB}$, and anti-poly ADP-ribose polymerase (PARP) MAB were from Sigma-Aldrich; Hybond-ECL-PVDF membranes and ECL-PRIME from GE Healthcare (Milan, Italy); antiERK polyclonal antibody and anti-phospho-ERK (Tyr204) MAB from Santa Cruz Biotechnology (DBA, Segrate, Milan, Italy); anti-Akt and anti-phospho-Akt (Ser473) polyclonal antibodies from Cell Signaling (Euroclone, Milan, Italy); goat anti-mouse and goat anti-rabbit HRP-conjugated antibodies from Transduction Laboratories (Lexington, KY, USA); protease inhibitor mixture from Roche Diagnostics; and BCA protein assay kit from Pierce (Celbio, Milan, Italy).

\section{Cell cultures}

TPC-1 and BCPAP cell lines from PTC were provided by Prof. A Fusco (University of Naples) and Dr E Puxeddu (University of Perugia) respectively and confirmed to have maintained their original genotype. TAD-2 cell line (immortalized, but not tumorigenic thyroid cells, obtained by Simian virus 40 infection of human fetal thyroid cells) was a gift of Prof. M Vitale (University of Salerno). TPC-1 and TAD-2 cells were grown in DMEM and BCPAP in RPMI culture medium (Gibco), each enriched with $10 \%$ fetal bovine serum (FBS), penicillin $(100 \mathrm{IU} / \mathrm{ml})$, streptomycin $(100 \mu \mathrm{g} / \mathrm{ml})$, and amphotericin B $(2.5 \mu \mathrm{g} / \mathrm{ml})$ (Sigma-Aldrich). Cells were kept in incubation at $37^{\circ} \mathrm{C}$ in an atmosphere of $5 \% \mathrm{CO}_{2}$.

Published by Bioscientifica Ltd 


\section{Cell growth assays}

To monitor cell viability, an MTT assay was performed as described previously (Celano et al. 2008) with small modifications. Briefly, cells were implanted in 96-well plates at a density of $6 \times 10^{3}$ for TPC- 1 and $8 \times 10^{3}$ for BCPAP and TAD-2. After $24 \mathrm{~h}$, cells were treated with different concentrations $(10,50$, and $100 \mu \mathrm{M})$ of OLE and Ac-OLE or equivalent dilution of ethanol (control) for $48 \mathrm{~h}$. Eight replicates were performed for each sample. Then medium was replaced with phenol red-free medium containing MTT $(0.5 \mathrm{mg} / \mathrm{ml})$. After 4-h incubation, $100 \mu \mathrm{l}$ 10\% SDS was added to each well and optical density was measured with a microplate spectrophotometer reader (X MARK Spectrophotometer Microplate Bio-Rad) at $\lambda=540$.

Cellular growth was also evaluated by counting the viable cells using the trypan blue exclusion method. TPC-1, BCPAP, and TAD-2 cell lines were seeded in 12-well plates at a density of $10^{4}$ for TPC- 1 and $4 \times 10^{4}$ for BCPAP and TAD-2. For non-proliferating cells, the experiments were performed in medium supplemented with only $0.1 \%$ FBS: in these conditions, the increase in cell number after $72 \mathrm{~h}$ was always lower than 5\%. After $24 \mathrm{~h}$, cells were treated as described earlier, resuspended in $0.4 \%$ trypan blue solution, and counted in a Burker chamber. Cellular proliferation was expressed as percent of live (non-stained) cells over control. Cell death rates were calculated as the percentage of stained cells over total cells and expressed as the ratio between treated and untreated (control) cells.

\section{Cell cycle analysis}

Cell cycle distribution was analyzed as described previously (Bulotta et al. 2011). Briefly, TPC-1 and BCPAP cells were either treated with ethanol and used as control, or with OLE and Ac-OLE (50 and $100 \mu \mathrm{M}$ ) for $48 \mathrm{~h}$. Then cells were harvested, washed twice with PBS, and fixed in $70 \%$ cold ethanol for at least $2 \mathrm{~h}$ at $-20^{\circ} \mathrm{C}$. Fixed cells were washed with PBS, incubated with $1 \mathrm{ml}$ PBS containing $0.5 \mu \mathrm{g} / \mathrm{ml}$ RNase A and $0.5 \%$ Triton X-100 for $30 \mathrm{~min}$ at $37^{\circ} \mathrm{C}$, and stained with $50 \mu \mathrm{g} / \mathrm{ml}$ propidium iodide. Cells were analyzed for DNA content by flow cytometry (FACScan, Becton Dickinson, San Jose, CA, USA) and the percentage of cells in various cell cycle phases was determined using Cell Quest software (Becton Dickinson).

\section{ROS assay}

Determination of ROS was founded on the oxidation of the cell-permeable non-fluorescent probe $\mathrm{H}_{2}$ DCF-DA.
Upon cleavage of the acetate groups by intracellular esterases and oxidation, it is converted to the highly fluorescent $2^{\prime}, 7^{\prime}$-dichlorofluorescein (DCF). For both TPC-1 and BCPAP cells, the experiments were performed in RPMI culture medium for its lower content of sodium bicarbonate (Odiatou et al. 2013). Cells were incubated for $48 \mathrm{~h}$ with 50 and $100 \mu \mathrm{M}$ OLE and Ac-OLE. At the end of the treatment, the cells were washed with PBS, trypsinized, resuspended in phenol red-free medium containing $\mathrm{H}_{2}$ DCF-DA $(25 \mu \mathrm{M})$ and incubated for $30 \mathrm{~min}$ at $37^{\circ} \mathrm{C}$. Subsequently, the cells were centrifuged, resuspended in PBS and, in the presence or not of $\mathrm{H}_{2} \mathrm{O}_{2}(100 \mu \mathrm{M}, 30 \mathrm{~min}$ of incubation), the fluorescence was evaluated by flow cytometric analysis using a FACScan laser flow cytometer equipped with Cell Quest software (Becton Dickinson).

\section{Protein extraction and western blot}

TPC-1 and BCPAP cells were seeded in six-well plates; after $24 \mathrm{~h}$, the medium was replaced with fresh medium containing OLE or Ac-OLE $(100 \mu \mathrm{M})$ or vehicle (ethanol) alone. After $30 \mathrm{~min}, 1-\mathrm{h}$, and 24-h incubation, cell monolayers were washed and solubilized in preheated denaturing buffer containing $50 \mathrm{mM}$ Tris-phosphate, $\mathrm{pH} 6.8,2 \%$ SDS, $10 \mathrm{mM} \mathrm{NaF}$, and a protease inhibitor mixture and immediately boiled as described previously (Bulotta et al. 2009). The cell lysates were quantified spectrophotometrically using the bicinchoninic acid procedure and samples were loaded and run onto $12 \%$ SDS-polyacrylamide gels. After electrophoresis, proteins were transferred to Hybond-ECL-PVDF membranes and incubated with antibodies specific for $\beta$-actin or the phosphorylated and non-phosphorylated forms of ERK and Akt proteins (D'Agostino et al. 2012). After incubation with the appropriate secondary antibodies, blots were developed with ECL-PRIME reagent.

\section{Statistical analysis}

The results are expressed as mean \pm s.D. of at least three independent experiments. The differences among treatments were evaluated with one-way ANOVA followed by the Tukey-Kramer multiple comparisons test.

\section{Results}

\section{Effects of OLE and Ac-OLE on thyroid cell proliferation}

MTT assays were performed to evaluate the effects of OLE and Ac-OLE on cellular proliferation by treating TPC-1,

Published by Bioscientifica Ltd. 

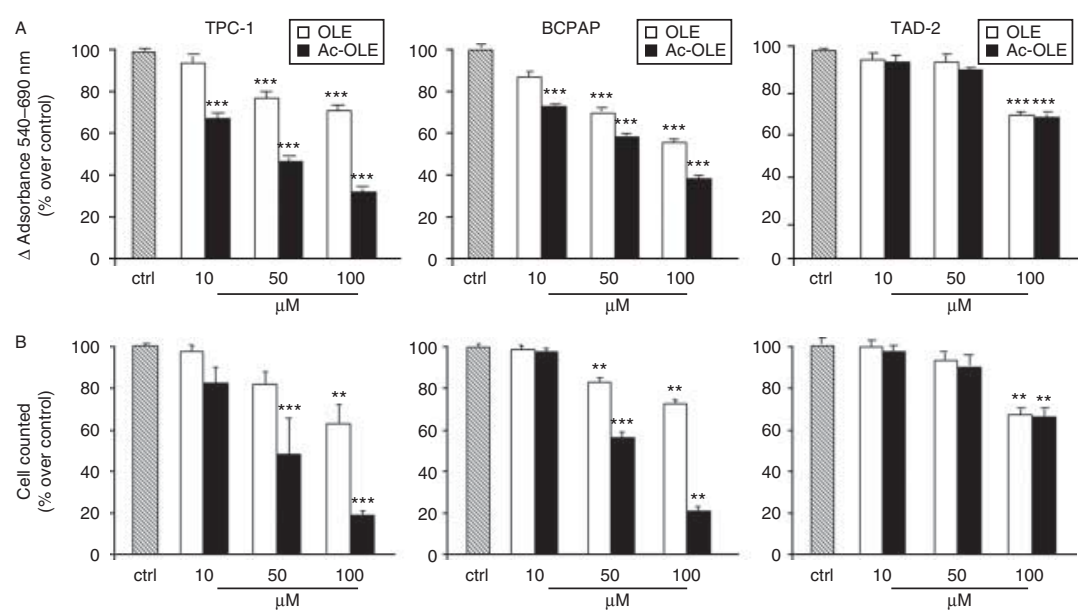

Figure 2

OLE and Ac-OLE effects on TPC-1, BCPAP, and TAD-2 cell viability. Cells were treated in the absence (ctrl) or presence of the indicated concentrations of the compounds for $48 \mathrm{~h}$. Viability was evaluated by MTT assay (A) and

BCPAP, and TAD-2 cells at various concentrations of the compounds for $48 \mathrm{~h}$. The treatment with OLE resulted in a significant dose-dependent growth inhibition in TPC-1 and BCPAP cell lines ( 30 and 40\% with 50 and $100 \mu \mathrm{M}$ vs control respectively) (Fig. 2A). Even stronger effects were detected with Ac-OLE, which determined a significant reduction in cell viability already at $10 \mu \mathrm{M}$ ( $\sim 30 \%$ reduction vs control) and elicited a $\sim 70 \%$ reduction at $100 \mu \mathrm{M}$ in both cell lines (Fig. 2A). Instead in non-tumor TAD- 2 cells, we observed a significant effect ( $\sim 25 \%$ reduction vs control) only with $100 \mu \mathrm{M}$ of both OLE and Ac-OLE (Fig. 2A). These results were confirmed using cell count (Fig. 2B). In addition, to test the effects of two compounds in non-proliferating cells, TPC-1 and BCPAP cells were grown in low-serum conditions $(0.1 \%$ FBS $)$. In such circumstances, Ac-OLE was still effective on BCPAP cells at $100 \mu \mathrm{M}$ with Ac-OLE (Fig. 3). By contrast, TPC-1 presented a higher rate of mortality so that the results could not be informative (data not shown).

To determine whether cellular growth inhibition was due to a block on cell cycle progression, TPC-1 and BCPAP cells were treated for $48 \mathrm{~h}$ with OLE and Ac-OLE and subjected to flow cytometric analysis (Fig. 4). In TPC-1 cells, OLE induced a mild block in S phase (Fig. 4A and C), while Ac-OLE induced a stronger dose-dependent $S$ phase arrest (Fig. 4A and C). Instead, BCPAP cells showed a minimal arrest in $\mathrm{G} 2 / \mathrm{M}$ phase after treatment with both compounds (Fig. 4B and C); in addition, $100 \mu \mathrm{M}$ concentration of Ac-OLE determined a cytotoxic effect (Fig. 4B and C). Increase in BCPAP cell mortality after $100 \mu \mathrm{M}$ Ac-OLE was confirmed by trypan blue exclusion cell count (B), as described in the Subjects and methods section. Values represent the mean \pm s.D. of three independent experiments. $* *, * * * P<0.01$ and $<0.001$ vs control respectively.

assay (Fig. 5A). Cellular death was not associated with apoptosis as shown by immunoblot analysis that revealed absence of PARP cleavage (Fig. 5B).

\section{Antioxidant effects of OLE and Ac-OLE}

Antioxidant effects were analyzed by determining ROS levels in TPC-1 and BCPAP cells treated with OLE and Ac-OLE using a cytofluorimetric analysis. In cells exposed to extracellular ROS attack $\left(\mathrm{H}_{2} \mathrm{O}_{2}, 100 \mu \mathrm{M}\right)$ (Fig. 6B), increase in ROS levels was revealed by rightward shift of

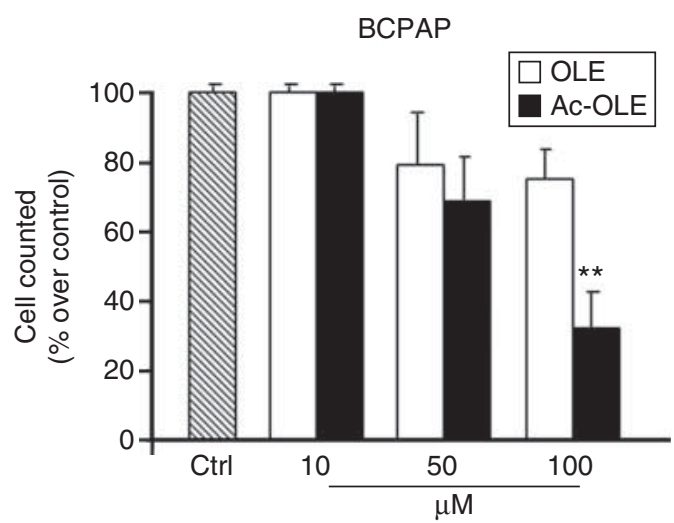

Figure 3

Effects of OLE and Ac-OLE on BCPAP cell viability in low-serum conditions. BCPAP cells were cultured in medium supplemented with only $0.1 \%$ FBS and treated or not (ctrl) with the compounds for $48 \mathrm{~h}$. Viability was determined by cell count, as described in the Subjects and methods section. $* * P<0.01$ vs control.

Published by Bioscientifica Ltd. 
A

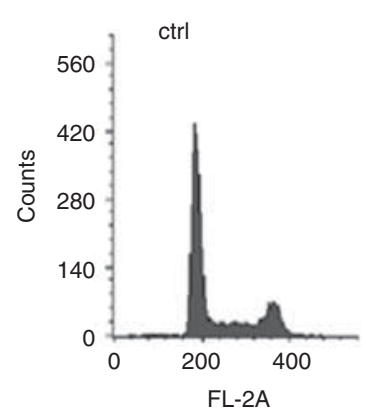

B

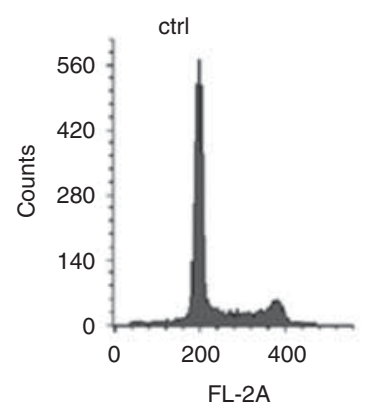

C

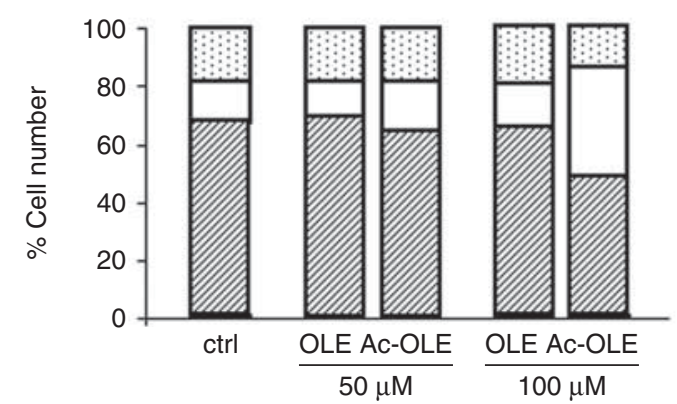

Figure 4

Effects of OLE and Ac-OLE on cell cycle progression. Cell lines were treated with the indicated concentrations of the compounds for $48 \mathrm{~h}$ and then analyzed by FACS ( $A$ and B) as indicated in the Subjects and methods

the fluorescence. In both cell lines, OLE treatment caused a decrease in ROS levels and a stronger effect appeared after incubation with Ac-OLE. In addition, Ac-OLE and not OLE treatment also caused a decrease in endogenous ROS levels in a dose-dependent way in both cell lines, as revealed by a leftward shift of fluorescence (Fig. 6A).

\section{OLE and Ac-OLE effects on ERK and Akt activation}

TPC-1 and BCPAP cells are characterized by RET/PTC1 rearrangement and $B R A F \mathrm{~V} 600 \mathrm{E}$ mutation respectively (Ribeiro et al. 2008, Schweppe et al. 2008) and present high-basal activation of the MEK/ERK and Akt signaling pathways. Thus, we investigated whether OLE and Ac-OLE
TPC-1
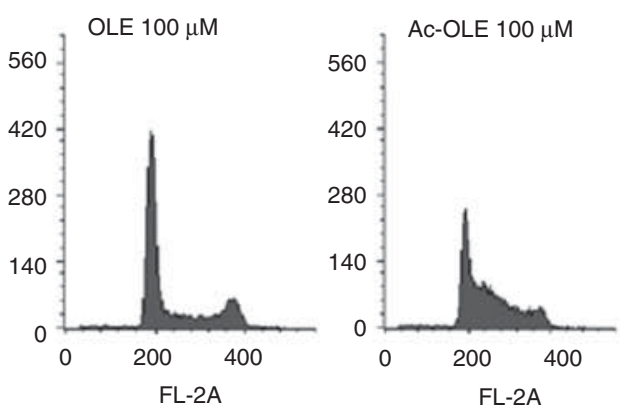

BCPAP
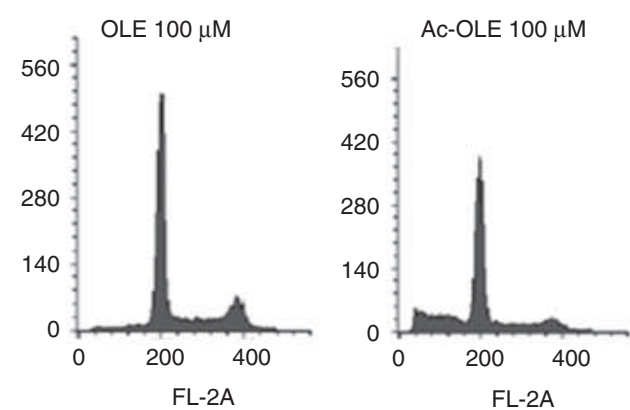

BCPAP

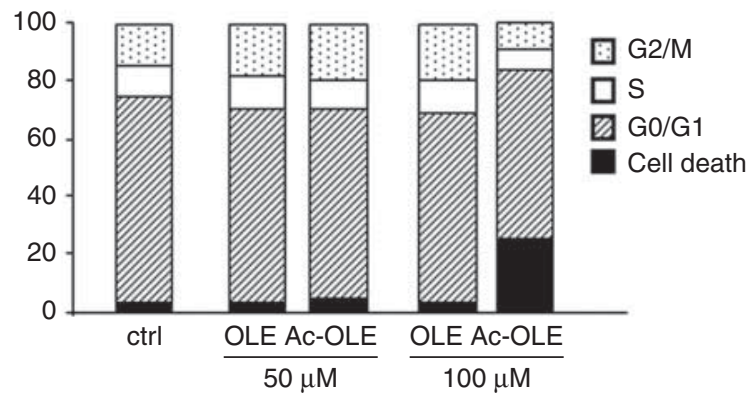

section. ctrl, cells without treatment. The bar graphs in C are representative of three independent experiments.

would affect these intracellular pathways by looking at the phosphorylation status of ERK and Akt. In TPC-1 cells, immunoblot experiments indicated that OLE at $100 \mu \mathrm{M}$ inhibited both ERK and Akt phosphorylation at 30 and 60 min followed by almost complete recovery after $24 \mathrm{~h}$ (Fig. 7, left panel). A stronger effect was observed treating the cells with Ac-OLE $100 \mu \mathrm{M}$ (Fig. 7, left panel). A similar inhibition occurred in BCPAP cells (Fig. 7, right panel): again both compounds induced an early reduction of phospho-ERK and phospho-Akt levels, but the effect of Ac-OLE on ERK phosphorylation was maintained even after $24 \mathrm{~h}$. Parallel immunoblots with antibodies against Akt and ERK proteins showed no changes in the total levels of these proteins (Fig. 7). 

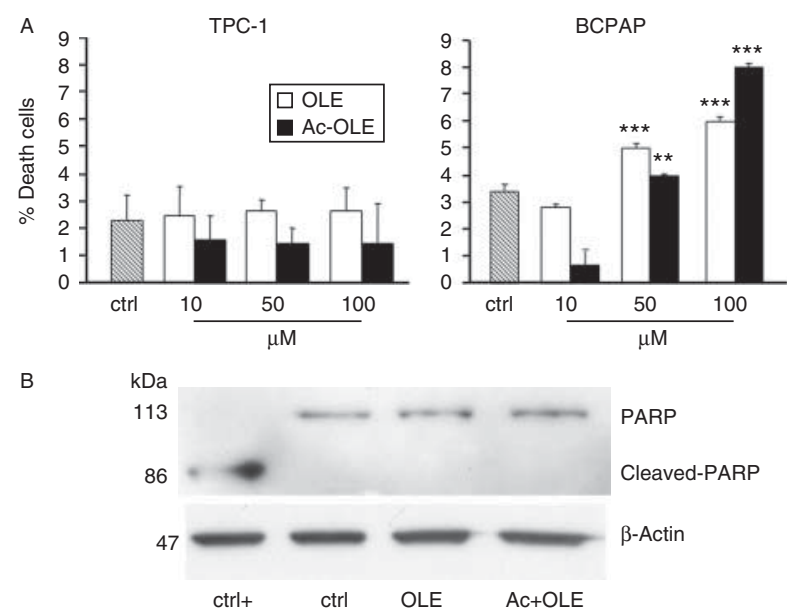

Figure 5

OLE and AC-OLE effects on cell death and apoptosis. (A) Mortality rates in TPC-1 and BCPAP cell lines treated with different concentrations of the compounds for $48 \mathrm{~h}$ were evaluated by trypan blue exclusion assay. ctrl, cells without treatment. $* *, * * * P<0.01$ and $<0.001$ vs control respectively. (B) Analysis of PARP cleavage after $48 \mathrm{~h}$ of treatment with $100 \mu \mathrm{M}$ OLE and AC-OLE was performed in protein extract by immunoblot. BCPAP cells treated with U0126 $(10 \mu \mathrm{M})$ were used as positive control $(c t r l+)$. Protein load was checked by $\beta$-actin immunostaining.

\section{Discussion}

Elucidation of the molecular abnormalities determining the development and progression of the most aggressive DTCs has helped to define novel targeted approaches against this subgroup of thyroid tumors. In particular, alterations of the RET-ras-raf-MAP kinase pathway, especially when associated with simultaneous activation of the PI3K-Akt pathway, characterize most of the lessdifferentiated thyroid tumors, unable to concentrate the iodine and therefore refractory to radioiodine treatment (Schlumberger \& Sherman 2012). Indeed, a direct link has been demonstrated between the presence of ras, BRAF, and RET/PTC activating alterations and the loss of the sodium/iodide symporter expression and/or function in the thyrocyte (Trapasso et al. 1999, Puxeddu et al. 2008). In any case, among the novel therapeutic approaches emerging from the results of the clinical trials including the radioiodine-refractory metastatic DTC (www.clinicaltrials.gov), the kinase inhibitors of the above-mentioned pathways do represent the most promising new targeted agents (Schlumberger \& Sherman 2012). However, the clinical trials have also revealed that the kinase inhibitors, even when initially effective, do not fully cure all DTC patients; moreover, there is yet a percentage of patients unresponsive to such a treatment, which is not completely free of side effects (Gild et al. 2011, Harris \& Bible 2011, Bible 2012). Thus, the search for novel approaches, other molecular targets, and potential new drugs for a better management of these unresponsive tumors is necessarily ongoing. Selected cytotoxic drugs are still demonstrating effectiveness in individual patients (Crouzeix et al. 2012, Spano et al. 2012), and the possibility to reduce the effective dosage to minimize their side effects by improving their delivery into cancer cells is also currently under investigation (Celano et al. 2004, Paolino et al. 2010). In addition, there are other molecular alterations that have been and are being taken into consideration as targets for novel treatments: among them, emphasis has been given to epigenetic changes involving DNA methylation or histone acetylation (Xing 2007, Russo et al. 2011) and, more recently, to damages induced by ROS production resulting by oxidative stress (Xing 2012). Interestingly, the ROS protumorigenic action has been proposed to be associated with the activation of MAPK- and Akt-dependent pathways (Xing 2012). In this view, antioxidant molecules appear as good candidates as therapeutic agents for refractory DTC hosting such alterations. Among the 'natural' antioxidant compounds under investigation as anticancer agents for various neoplasia, we focused our attention on OLE, a phenolic derivative of virgin olive oil, whose antioxidant activity and antiproliferative effects have been demonstrated in many preclinical models of cancer disease (Visioli et al. 2002, El \& Karakaya 2009, Cicerale et al. 2010).

Herein, we demonstrate that OLE is able to reduce the proliferation of TPC-1 and BCPAP thyroid cancer cells at micromolar concentrations, doses similar to those used in other tumor cellular models (Goulas et al. 2009, Notarnicola et al. 2010), while only mild effects have been detected in the non-tumor TAD-2 cell line. This effect is associated with a reduction of $\mathrm{H}_{2} \mathrm{O}_{2}$-induced ROS levels and phosphorylation of ERK and Akt. Regarding the latter finding, it should be remembered that TPC- 1 and BCPAP cells host the RET/PTC rearrangement and BRAF V600E mutation respectively (Ribeiro et al. 2008, Schweppe et al. 2008), two genetic alterations detected in PTCs resulting in the oncogene-driven activation of the growth-promoting and anti-apoptotic pathways occurring in thyroid tumorigenesis (Knauf \& Fagin 2009). Interestingly, the capacity of OLE to block ERK activation has also been reported in breast cancer MCF-7 cells stimulated by estradiol (Sirianni et al. 2010).

Moreover, our data show that OLE effects are further improved by its peracetylation. Such a chemical modification has been previously demonstrated to improve its

Published by Bioscientifica Ltd 
A
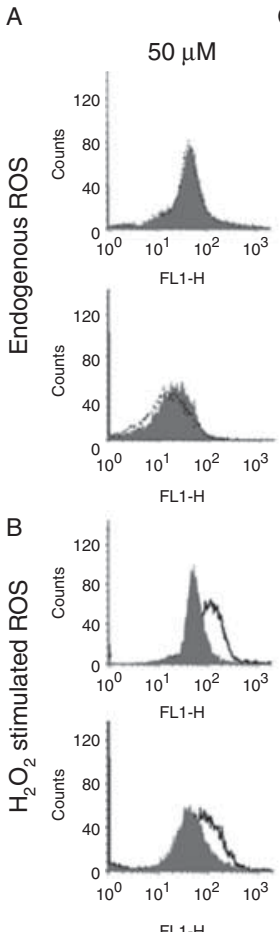

OLE
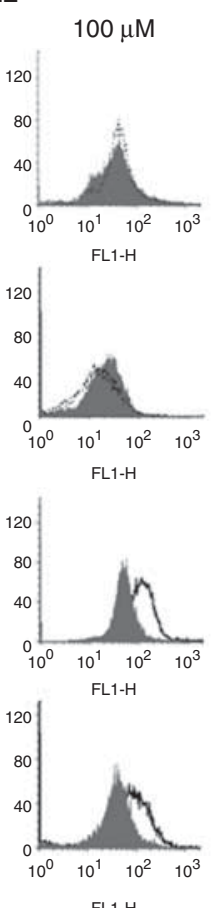

Figure 6

ROS determination in TPC- 1 and BCPAP cell lines. Cells were pretreated for $48 \mathrm{~h}$ without or with the indicated concentrations of OLE and AC-OLE,

incubated with $\mathrm{H}_{2}$ DCF-DA and the fluorescence of DCF was evaluated by flow

permeability (Procopio et al. 2009), still maintaining the biological antioxidant activity of the parent compound, probably because of extensive deacetylation of hydroxytyrosol acetate by carboxylesterases. Such deacetylation can take place either within the cell, upon absorption of the acetylated molecule, or in the extracellular space by secreted esterases (Mateos et al. 2005). Furthermore, the abundance of OLE in olive leaves, a discard product of the olive oil production industry, together with the Green

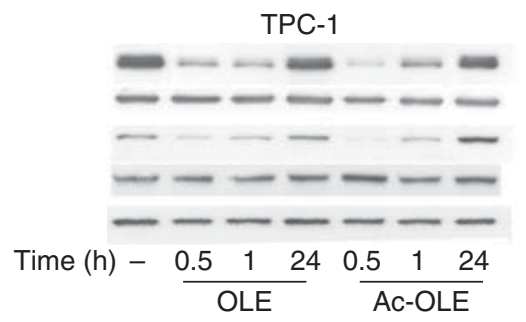

\section{Figure 7}

Effects of OLE and its peracetylated form, Ac-OLE, on ERK and Akt phosphorylation. TPC-1 and BCPAP cells were treated in the absence or presence of the compounds at $100 \mu \mathrm{M}$. Immunoblots were performed as described in the Subjects and methods section. At the indicated time,
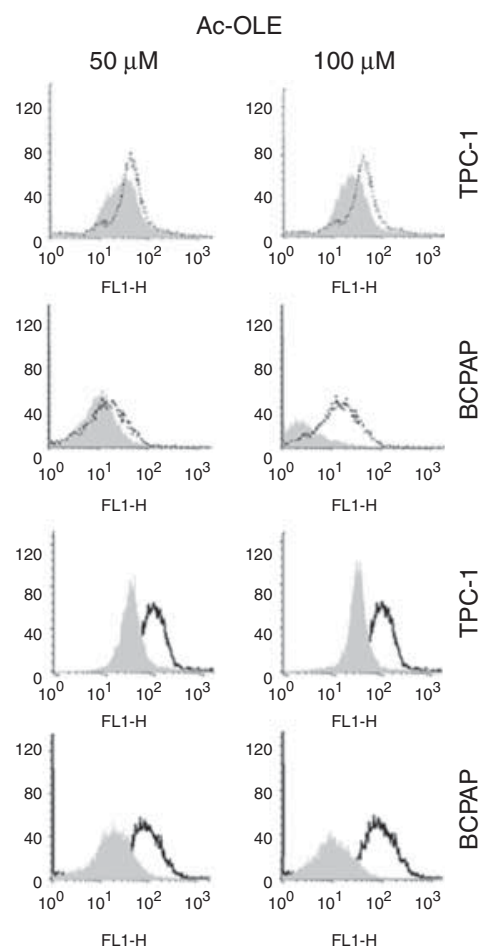

cytometry. (A) Endogenous ROS levels. (B) ROS levels were evaluated after oxidative stimulus $\left(\mathrm{H}_{2} \mathrm{O}_{2}, 100 \mu \mathrm{M}\right)$ for $30 \mathrm{~min}$ (dotted areas, no treatment; open space areas, $\mathrm{H}_{2} \mathrm{O}_{2}$; dark grey areas, OLE; light grey areas, Ac-OLE).

Chemistry-based technique of extraction and semisynthetic processes, accomplish many Green Chemistry tasks and demonstrate the possibility to develop sustainable complex protocols using some non-conventional techniques. It is noteworthy to remind the absence of toxicity of OLE, as documented by in vivo studies (Hamdi \& Castellon 2005, El \& Karakaya 2009, Cicerale et al. 2010). Enrichment of olive oil or other food components with such compounds has been already efficaciously tested,

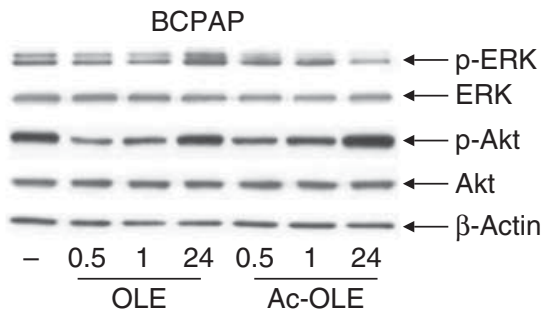

cell lysates were prepared and analysis of active, phosphorylated ERK (p-ERK) and phosphorylated Akt (p-Akt), and total form of the enzymes (ERK, Akt), was performed by western blotting. Protein load was checked by $\beta$-actin immunostaining.

Published by Bioscientifica Ltd. 
providing preliminary useful information in view of their administration to patients (Markopoulos et al. 2009, Achat et al. 2012). Further studies, using in vivo experimental models of thyroid tumors, will shed more light on the possibility of including these molecules in the class of targeted therapeutics to test alone and/or in combination for treatment of radioiodine-refractory DTCs.

\section{Declaration of interest}

The authors declare that there is no conflict of interest that could be perceived as prejudicing the impartiality of the research reported.

\section{Funding}

This work was supported by Fondazione 'Umberto Di Mario' ONLUS.

\section{References}

Achat S, Tomao V, Madani K, Chibane M, Elmaataoui M, Dangles O \& Chemat F 2012 Direct enrichment of olive oil in oleuropein by ultrasound-assisted maceration at laboratory and pilot plant scale. Ultrasonics Sonochemistry 19 777-786. (doi:10.1016/j.ultsonch.2011. 12.006)

Bible KC 2012 Individualization of therapies for patients with advanced differentiated thyroid cancers. Journal of Clinical Endocrinology and Metabolism 97 3092-3093. (doi:10.1210/jc.2012-2676)

Bulotta S, Ierardi MV, Maiuolo J, Cattaneo MG, Cerullo A, Vicentini LM \& Borgese N 2009 Basal nitric oxide release attenuates cell migration of HeLa and endothelial cells. Biochemical and Biophysical Research Communications 386 744-749. (doi:10.1016/j.bbrc.2009.06.118)

Bulotta S, Corradino R, Celano M, D'Agostino M, Maiuolo J, Oliverio M, Procopio A, Iannone M, Rotiroti D \& Russo D 2011 Antiproliferative and antioxidant effects of oleuropein and its semisynthetic peracetylated derivatives on breast cancer cells. Food Chemistry 127 1609-1614. (doi:10.1016/j.foodchem.2011.02.025)

Celano M, Calvagno MG, Bulotta S, Paolino D, Arturi F, Rotiroti D, Filetti S, Fresta M \& Russo D 2004 Cytotoxic effects of Gemcitabine-loaded liposomes in human anaplastic thyroid carcinoma cells. BMC Cancer $\mathbf{4}$ 63. (doi:10.1186/1471-2407-4-63)

Celano M, Schenone S, Cosco D, Navarra M, Puxeddu E, Racanicchi L, Brullo C, Varano E, Alcaro S, Ferretti E et al. 2008 Cytotoxic effects of a novel pyrazolopyrimidine derivative entrapped in liposomes in anaplastic thyroid cancer cells in vitro and in xenograft tumors in vivo. Endocrine-Related Cancer 15 499-510. (doi:10.1677/ERC-07-0243)

Cicerale S, Lucas L \& Keast R 2010 Biological activities of phenolic compounds present in virgin olive oil. International Journal of Molecular Sciences 11 458-479. (doi:10.3390/ijms11020458)

Crouzeix G, Michels JJ, Sevin E, Aide N, Vaur D \& Bardet S 2012 Unusual short-term complete response to two regimens of cytotoxic chemotherapy in a patient with poorly differentiated thyroid carcinoma. Journal of Clinical Endocrinology and Metabolism 97 3046-3050. (doi:10.1210/jc.2012-1630)

D'Agostino M, Voce P, Celano M, Sponziello M, Moretti S, Maggisano V, Verrienti A, Durante C, Filetti S, Puxeddu E et al. 2012 Sunitinib exerts only limited effects on the proliferation and differentiation of anaplastic thyroid cancer cells. Thyroid 22 138-144. (doi:10.1089/thy. 2011.0060)

Duracková Z 2010 Some current insights into oxidative stress. Physiological Research 59 459-469.
El SN \& Karakaya S 2009 Olive tree (Olea europaea) leaves: potential beneficial effects on human health. Nutrition Reviews 67 632-638. (doi:10.1111/j.1753-4887.2009.00248.x)

Fagin JA \& Mitsiades N 2008 Molecular pathology of thyroid cancer: diagnostic and clinical implications. Best Practice \& Research. Clinical Endocrinology \& Metabolism 22 955-969. (doi:10.1016/j.beem.2008. 09.017)

Gild ML, Bullock M, Robinson BG \& Clifton-Bligh R 2011 Multikinase inhibitors: a new option for the treatment of thyroid cancer. Nature Reviews. Endocrinology 7 617-624. (doi:10.1038/nrendo.2011.141)

Goulas V, Exarchou V, Troganis AN, Psomiadou E, Fotsis T, Briasoulis E \& Gerothanassis IP 2009 Phytochemicals in olive-leaf extracts and their antiproliferative activity against cancer and endothelial cells. Molecular Nutrition \& Food Research 53 600-608. (doi:10.1002/mnfr.200800204)

Hall SF, Walker H, Siemens R \& Schneeberg A 2009 Increasing detection and increasing incidence in thyroid cancer. World Journal of Surgery 33 2567-2571. (doi:10.1007/s00268-009-0226-9)

Hamdi HK \& Castellon R 2005 Oleuropein, a non-toxic olive iridoid, is an anti-tumor agent and cytoskeleton disruptor. Biochemical and Biophysical Research Communications 334 769-778. (doi:10.1016/j.bbrc.2005.06.161)

Harris PJ \& Bible KC 2011 Emerging therapeutics for advanced thyroid malignancies: rationale and targeted approaches. Expert Opinion on Investigational Drugs 20 1357-1375. (doi:10.1517/13543784.2011. 614230)

Knauf JA \& Fagin JA 2009 Role of MAPK pathway oncoproteins in thyroid cancer pathogenesis and as drug targets. Current Opinion in Cell Biology 21 296-303. (doi:10.1016/j.ceb.2009.01.013)

Markopoulos C, Vertzoni M, Agalias A, Magiatis P \& Reppas C 2009 Stability of oleuropein in the human proximal gut. Journal of Pharmacy and Pharmacology 61 143-149. (doi:10.1211/jpp.61.02.0002)

Mateos M, Goya L \& Bravo L 2005 Metabolism of the olive oil phenols hydroxytyrosol, tyrosol, and hydroxytyrosyl acetate by human hepatoma HepG2 cells. Journal of Agricultural and Food Chemistry $\mathbf{5 3}$ 9897-9905. (doi:10.1021/jf051721q)

Notarnicola M, Pisanti S, Tutino V, Bocale D, Rotelli MT, Gentile A, Memeo V, Bifulco M, Perri E \& Caruso MG 2010 Effects of olive oil polyphenols on fatty acid synthase gene expression and activity in human colorectal cancer cells. Genes \& Nutrition 6 63-69. (doi:10.1007/s12263-010-0177-7)

Odiatou EM, Skaltsounis AL \& Constantinou AI 2013 Identification of the factors responsible for the in vitro pro-oxidant and cytotoxic activities of the olive polyphenols oleuropein and hydroxytyrosol. Cancer Letters 330 113-121. (doi:10.1016/j.canlet.2012.11.035)

Paolino D, Cosco D, Racanicchi L, Trapasso E, Celia C, Iannone M, Puxeddu E, Costante G, Filetti S, Russo D et al. 2010 Gemcitabineloaded PEGylated unilamellar liposomes vs GEMZAR ${ }^{\circledR}$ : biodistribution, pharmacokinetic features and in vivo antitumor activity. Journal of Controlled Release 144 144-150. (doi:10.1016/j.jconrel.2010.02.021)

Procopio A, Sindona G, Gaspari M, Costa N \& Nardi M 2008 Chemicalcatalytic method 286 for the peracylation of oleuropein and its products of hydrolysis. International Patent no. 287 PCT/IT2008/000303.

Procopio A, Alcaro S, Nardi M, Oliverio M, Ortuso F, Sacchetta P, Pieragostino D \& Sindona G 2009 Synthesis, biological evaluation, and molecular modeling of oleuropein and its semisynthetic derivatives as cyclooxygenase inhibitors. Journal of Agricultural and Food Chemistry $\mathbf{5 7}$ 11161-11167. (doi:10.1021/jf9033305)

Puxeddu E, Durante C, Avenia N, Filetti S \& Russo D 2008 Clinical implication of BRAF mutation in thyroid carcinoma. Trends in Endocrinology and Metabolism 19 138-145. (doi:10.1016/j.tem.2007.12.003)

Ribeiro FR, Meireles AM, Rocha AS \& Teixeira MR 2008 Conventional and molecular cytogenetics of human non-medullary thyroid carcinoma: characterization of eight cell line models and review of the literature on clinical samples. BMC Cancer 8 371. (doi:10.1186/1471-2407-8-371)

Russo D, Damante G, Puxeddu E, Durante C \& Filetti S 2011 Epigenetics of thyroid cancer and novel therapeutic targets. Journal of Molecular Endocrinology 46 R73-R81. (doi:10.1530/JME-10-0150) 
Schlumberger M \& Sherman SI 2009 Clinical trials for progressive differentiated thyroid cancer: patient selection, study design, and recent advances. Thyroid 19 1393-1400. (doi:10.1089/thy. 2009.1603)

Schlumberger M \& Sherman SI 2012 Approach to the patient with advanced differentiated thyroid cancer. European Journal of Endocrinology 166 5-11. (doi:10.1530/EJE-11-0631)

Schlumberger M, Lacroix L, Russo D, Filetti S \& Bidart JM 2007 Defects in iodide metabolism in thyroid cancer and implications for the follow-up and treatment of patients. Nature Clinical Practice. Endocrinology \& Metabolism 3 260-269. (doi:10.1038/ncpendmet0449)

Schweppe RE, Klopper JP, Korch C, Pugazhenthi U, Benezra M, Knauf JA, Fagin JA, Marlow LA, Copland JA, Smallridge RC et al. 2008 Deoxyribonucleic acid profiling analysis of 40 human thyroid cancer cell lines reveals cross-contamination resulting in cell line redundancy and misidentification. Journal of Clinical Endocrinology and Metabolism 93 4331-4341. (doi:10.1210/jc.2008-1102)

Sirianni R, Chimento A, De Luca A, Casaburi I, Rizza P, Onofrio A, Iacopetta D, Puoci F, Andò S, Maggiolini M et al. 2010 Oleuropein and hydroxytyrosol inhibit MCF-7 breast cancer cell proliferation interfering with ERK1/2 activation. Molecular Nutrition \& Food Research 54 833-840. (doi:10.1002/mnfr.200900111)

Spano JP, Vano Y, Vignot S, De La Motte Rouge T, Hassani L, Mouawad R, Menegaux F, Khayat D \& Leenhardt L 2012 GEMOX regimen in the treatment of metastatic differentiated refractory thyroid carcinoma. Medical Oncology 29 1421-1428. (doi:10.1007/s12032-011-0070-2)

Trapasso F, Iuliano R, Chiefari E, Arturi F, Stella A, Filetti S, Fusco A \& Russo D 1999 Iodide symporter gene expression in normal and transformed rat thyroid cells. European Journal of Endocrinology 140 447-451. (doi:10.1530/eje.0.1400447)

Visioli F, Poli A \& Galli C 2002 Antioxidant and other biological activities of phenols from olives and olive oil. Medicinal Research Reviews 22 65-75. (doi:10.1002/med.1028)

Wang D, Feng JF, Zeng P, Yang YH, Luo J \& Yang YW 2011 Total oxidant/antioxidant status in sera of patients with thyroid cancers. Endocrine-Related Cancer 18 773-782. (doi:10.1530/ERC-11-0230)

Xing M 2007 Gene methylation in thyroid tumorigenesis. Endocrinology 148 948-953. (doi:10.1210/en.2006-0927)

Xing M 2012 Oxidative stress: a new risk factor for thyroid cancer. Endocrine-Related Cancer 19 C7-C11. (doi:10.1530/ERC-11-0360)

Received in final form 15 May 2013

Accepted 29 May 2013

Accepted Preprint published online 29 May 2013
(C) 2013 Society for Endocrinology Printed in Great Britain
Published by Bioscientifica Ltd. 